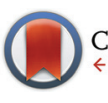

CrossMark -click for updates

Cite this: Dalton Trans., 2016, 45 6044

Received 17th July 2015,

Accepted 3rd August 2015

DOI: $10.1039 / c 5 d t 02711 j$

www.rsc.org/dalton

\title{
Reduction of dichloro(diaza-phospha)stibanes - isolation of a donor-stabilized distibenium dication $\uparrow+$
}

\begin{abstract}
Alexander Hinz, ${ }^{a}$ Julia Rothe, ${ }^{b}$ Axel Schulz ${ }^{\star a, b}$ and Alexander Villinger ${ }^{a}$
A reaction of antimonytrichloride $\mathrm{SbCl}_{3}$ with potassium bis(terphenylimino)phosphide $\mathrm{K}\left[(T e r N)_{2} \mathrm{P}\right]$ smoothly afforded a novel class of mixed diazadipnictanes, namely dichloro(diaza-phospha)stibane $\left[\mathrm{Ter}_{2} \mathrm{~N}_{2} \mathrm{P}^{(\mathrm{IIII})} \mathrm{Sb}^{(\mathrm{III})} \mathrm{Cl}_{2}\right]$, which is considered to exist as open chain-like and cyclic isomers in an equilibrium. $\left[\mathrm{Ter}_{2} \mathrm{~N}_{2} \mathrm{PSbCl}_{2}\right]$ is a versatile starting material for reduction and halide abstraction experiments. Halide abstraction led to the formation of a cyclic diazastibaphosphenium cation $\left[\mathrm{P}(\mu-\mathrm{NTer})_{2} \mathrm{SbCl}\right]^{+}$. Upon reduction of $\left[\mathrm{Ter}_{2} \mathrm{~N}_{2} \mathrm{PSbCl}_{2}\right]$, the transient existence of the novel mixed biradicaloid $\left[\mathrm{P}(\mu-\mathrm{NTer})_{2} \mathrm{Sb}\right]$ was proven by a trapping experiment with an alkyne, while reduction in the absence of trapping agents afforded the eight-membered heterocycle $\left[\mathrm{Sb}_{2}-\left\{\mu-(\mathrm{TerN})_{2} \mathrm{P}\right\}_{2}\right]$. This constitutional isomer of a dimerized biradicaloid features a bonding situation that indicates the presence of a donor-stabilized $\left[\mathrm{Sb}_{2}\right]^{2+}$ ion.
\end{abstract}

\section{Introduction}

As early as 1894 Michaelis and Schroeter discovered the first dichloro-diphosphadiazane (Fig. 1, species $\mathbf{A}$ with $\mathrm{R}=\mathrm{Ph}$ ) upon reaction of aniline hydrochloride with phosphorus(III) chloride. ${ }^{1}$ Nowadays, these species are well known with respect to their oxidation, substitution, halide abstraction and coordination behaviour. ${ }^{2}$ Only in the early 1980 s, Paine et al. investigated the reduction of such cyclic species, ${ }^{3-5}$ which led to the isolation of $\alpha-(\mathrm{RN})_{4} \mathrm{P}_{4}\left(\mathrm{C}, \mathrm{R}={ }^{t} \mathrm{Bu}\right)$, with a $\mathrm{P}_{4} \mathrm{~N}_{4}$ core isostructural to $\alpha-\mathrm{P}_{4} \mathrm{~S}_{4}$ and $\mathrm{S}_{4} \mathrm{~N}_{4} \cdot{ }^{6}$ Later, Wright et al. were able to convert the $\alpha$ - into the $\beta$-isomer photochemically (D). ${ }^{7}$ However, upon reduction of a dichloro-diphosphadiazane, in the first step a biradicaloid (species B) is formed. If the steric bulk of the substituent is sufficient to prevent dimerization, these biradicaloids can be isolated, e.g. 1,3-diphospha-2,4diazane-1,3-diyl $[\mathrm{P}(\mu \text {-NTer })]_{2} \quad$ (Ter $=2,6$-dimesityl-phenyl $){ }^{8}$ Singlet biradicaloids fascinated chemists in theory and synthesis equally in the past few decades since they are highly reactive species and putative intermediates in the processes of

\footnotetext{
${ }^{a}$ Institut für Chemie, Universität Rostock, Albert-Einstein-Str. 3a, 18059 Rostock, Germany.E-mail: axel.schulz@uni-rostock.de

${ }^{b}$ Abteilung Materialdesign, Leibniz-Institut für Katalyse e.V. an der Universität Rostock, Albert-Einstein-Str. 29a, 18059 Rostock, Germany

$\dagger$ This contribution is dedicated to Prof. Dr Ekkehart Hahn on the occasion of his $60^{\text {th }}$ birthday.

\$Electronic supplementary information (ESI) available: Additional experimental details, full characterization of all compounds and computational details. CCDC 1404259-1404264. For ESI and crystallographic data in CIF or other electronic format see DOI: $10.1039 / \mathrm{c} 5 \mathrm{dt} 02711 \mathrm{j}$
}
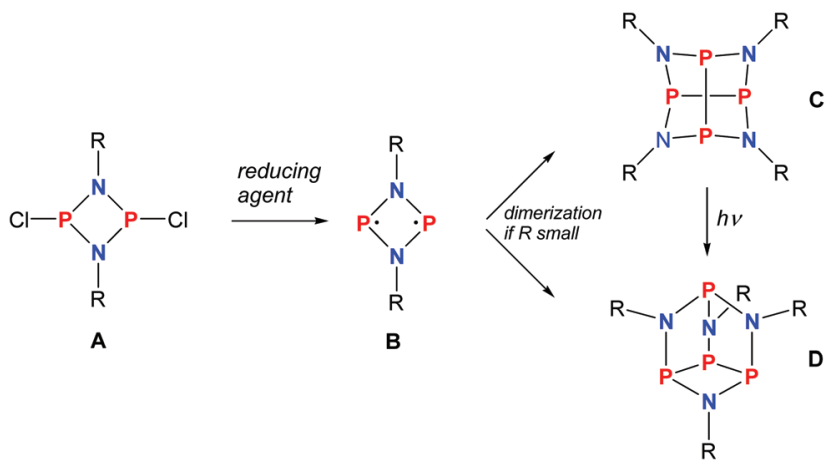

Fig. 1 Reduction of cyclodichlorodiphosphadiazane A yielding biradicloid B or its dimers C and D depending on the steric strain.

bond breaking and bond formation. ${ }^{9-11}$ The term biradicaloids used throughout this paper refers to a subset of biradicals with two radical centers interacting significantly. Pioneering work in this field was carried out by Niecke et al. who discovered 1,3-dichloro-2,4-diphosphacyclobutane-1,3-diyl [ClC$\left(\mu\right.$-PMes $\left.\left.{ }^{*}\right)\right]_{2}$ (Fig. 2 species E, Mes ${ }^{*}=2,4,6$-tri- ${ }^{\text {tert }}$ butyl-phenyl) in $1995 .^{12}$ The reactivity of this particular biradicaloid was investigated with respect to photochemical isomerization, reduction and oxidation as well as acid-base reactivity afterwards. ${ }^{13-17}$ Yoshifuji et al. reported on a different synthetic approach to a 1,3-diphosphacyclobutane-2,4-diyl (F) bearing the bulky substituent not on the phosphorus but on the carbon atom. ${ }^{18-23}$ In 2002, Bertrand et al. succeeded in the isolation of another biradicaloid, $\left[{ }^{\mathrm{i}} \mathrm{Pr}_{2} \mathrm{P}\left(\mu-\mathrm{B}{ }^{t} \mathrm{Bu}\right)\right]_{2}$ (G), which featured intriguing bond-stretch isomerism in dependence of 
<smiles>[Na][P+]1([Mg])C(Cl)=[PH]1Cl</smiles>

E

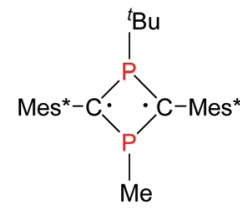

$\mathbf{F}$

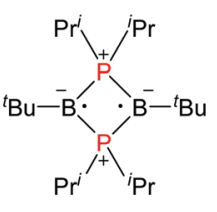

G

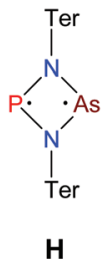

H
Fig. 2 Selected known biradicaloids.

the steric congestion upon changing the substituents. ${ }^{24,25}$ Furthermore, radical-type as well as ionic-type characteristic reactions were observed. ${ }^{26,27}$ In the groups of Power and Schnepf, several biradicaloid main group cluster compounds were investigated. ${ }^{28-30}$

Currently, several examples of cyclobutane-1,3-diyl derivatives are known (Fig. 2), ${ }^{31-37}$ however all known singlet biradicaloids feature equivalent radical centres. The first biradicaloid with different radical centres, 1-arsa-3-phospha2,4-diazane-1,3-diyl $\left[\mathrm{P}(\mu \text {-NTer })_{2} \mathrm{As}\right](\mathbf{H})$, was recently obtained by reduction of a cyclic dichloro-arsa-phospha-diazane and features remarkable regioselectivity in the activation of small molecules. ${ }^{38}$ To evoke even larger differences between the radical centres, we sought to generate 1-stiba-3-phospha-2,4diazane-1,3-diyl $[\mathrm{P}(\mu$-NTer $) \mathrm{Sb}]$, which is in the focus of this contribution.

\section{Results and discussion}

\section{Synthesis of NPN-substituted dichlorostibanes}

The reaction of potassium bis(terphenylimino)phosphide $\left(\mathrm{K}\left[(\mathrm{TerN})_{2} \mathrm{P}\right], \mathbf{1}, \delta\left({ }^{31} \mathrm{P}\right) 322 \mathrm{ppm}, \text { Fig. } 3\right)^{38}$ with antimony(III) chloride in toluene at ambient temperature led to the formation of a mixture of two constitutional isomers: (i) openchain dichlorostibane 2a (Fig. 3) and trans-2b as indicated by temperature variable ${ }^{31} \mathrm{P}$ NMR studies (Fig. 4).

The redissolved compound 2 exhibits a very broad ${ }^{31} \mathrm{P}$ NMR resonance (Fig. 4, $\delta\left({ }^{31} \mathrm{P}, 300 \mathrm{~K}, 500 \mathrm{MHz}\right)=332 \mathrm{ppm}, \nu_{1 / 2}=900$ $\mathrm{Hz}$ ) under ambient conditions indicating intramolecular dynamics. To shed some light into this dynamics, density functional theory at the pbe1pbe level (for details see the ESI was applied to study the potential energy surface (PES) of $\mathbf{2 M}$ (Fig. 5, M = model with the terphenyl group substituted by phenyl). ${ }^{39,40}$ In the gas phase, initially three isomers of $\mathbf{2 M}$

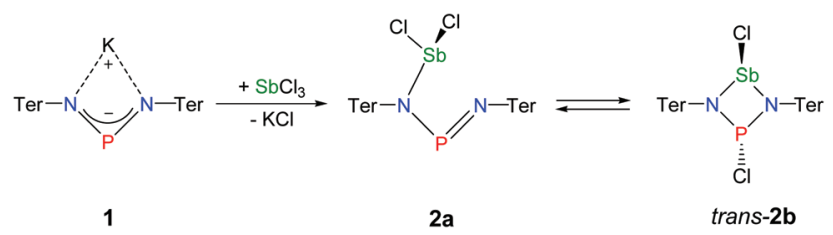

Fig. 3 Preparation of NPN-substituted dichlorostibane $2 a$ and its equilibrium with trans-2b as indicated by ${ }^{31} \mathrm{P}$ NMR studies.

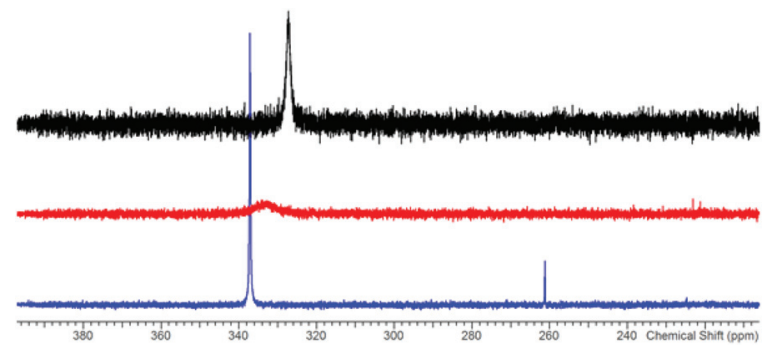

Fig. $4{ }^{31} \mathrm{P}$ NMR spectra of 2 in $\left[D_{8}\right]$-toluene at -80 (blue), +20 (red), and $+100^{\circ} \mathrm{C}$ (black).

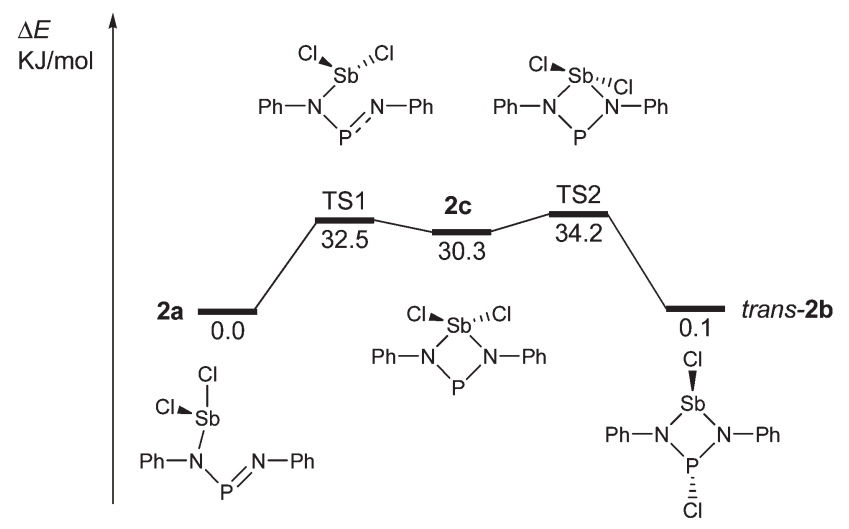

Fig. 5 Potential energy surface of $2 \mathrm{M}$ ( $M=$ model, terphenyl group substituted by phenyl; the isomerisation process, leading to cis-2b, was omitted for clarity, see the ESI; $;$ TS = transition state).

were considered: 2a, as well as the cyclic 1,3-dichloro-1-stiba3-phospha-2,4-diazanes cis- and trans-[ClP $\left.(\mu-\mathrm{NPh})_{2} \mathrm{SbCl}\right] 2 \mathbf{b}$. These three isomers were found to be very similar in energy (relative to $2 \mathrm{a}$ : cis-2b +2.6 , trans- $2 \mathrm{~b}+0.1 \mathrm{~kJ} \mathrm{~mol}^{-1}$ ). In addition, a higher-lying cyclic isomer $2 \mathrm{c}\left(30.3 \mathrm{~kJ} \mathrm{~mol}^{-1}\right)$ bearing a $\mathrm{SbCl}_{2}$ group was located at the PES when studying the intrinsic reaction for the different isomerization processes as depicted in Fig. 5. Isomer $2 \mathrm{c}$ is a typical intermediate lying in a very shallow energy valley, therefore cannot be observed in the ${ }^{31} \mathrm{P}$ NMR spectra. At low temperatures, two singlets were observed in the ${ }^{31} \mathrm{P}$ NMR spectra of a sample of redissolved crystalline 2a (193 K, 337.1 and $261.2 \mathrm{ppm}$ ), which were assigned to 2a and trans-2b (computed $\delta\left({ }^{31} \mathrm{P}\right)$ : cis-2b 242, trans-2b 262, 2a $333 \mathrm{ppm})$. At $-80{ }^{\circ} \mathrm{C}$, a ratio of $18: 1$ was found for both species, so the coalesced signal is expected to occur at $331.2 \mathrm{ppm}$ (observed at $100{ }^{\circ} \mathrm{C}$ : $327.2 \mathrm{ppm}$ ). We do want to stress that the assignment of trans-2b to the NMR resonance at $261.2 \mathrm{ppm}$ is solely based on comparison with computational data. The ${ }^{31} \mathrm{P}$ NMR data with a coalescence temperature of $313 \mathrm{~K}$ indicate a Gibbs activation energy for the rearrangement reaction $2 \mathbf{a} \rightarrow$ trans-2b of $49.5 \mathrm{~kJ} \mathrm{~mol}^{-1}$. From a van't Hoff plot, the difference in the energy of both isomers was estimated to be $6.2 \mathrm{~kJ} \mathrm{~mol}^{-1}$ ( $c f . \Delta E(0 \mathrm{~K})=0.1 \mathrm{~kJ} \mathrm{~mol}^{-1}$ for the gas phase). Interestingly, single crystal $\mathrm{X}$-ray studies revealed the exclusive 

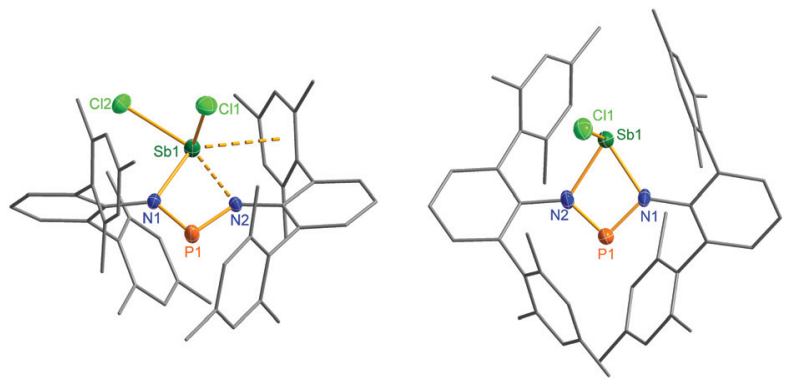

Fig. 6 Molecular structure of $2 a$ (left) and 3 (right). Thermal ellipsoids are drawn at $50 \%$ probability $(173 \mathrm{~K})$. Selected bond lengths $[\AA \AA]$ and angles [º: 2: Sb1-N1 2.133(4), Sb1-N2 2.392(4), Sb1-Cl1 2.358(2), Sb1$\mathrm{Cl} 2$ 2.451(2), P1-N1 1.623(4), P1-N2 1.598(4), N2-P1-N1 96.0(2). 3: Sb1-N1 2.136(3), Sb1-N2 2.171(3), Sb1-Cl1 2.342(1), P1-N2 1.625(3), P1N1 1.643(4), N2-P1-N1 91.7(2).

presence of thermodynamically more stable open-chain species 2a in the solid state (yield: 72\%, Fig. 6 left). The thermodynamical preference of the open chain species 2 a over $\mathbf{2 b}$ and $\mathbf{2 c}$ is a clear difference to the lighter homologues. For example, the reaction of $\mathbf{1}$ with arsenic(III) chloride led to the formation of the cyclic arsa-phospha-diazane [ClP$\left.(\mu-\mathrm{NTer})_{2} \mathrm{AsCl}\right] .^{38}$

The structural motif observed for 2 a resembles the recently studied NCN-substituted $\mathrm{LSbCl}_{2}$-compounds (e.g. $\mathrm{L}=$ amidinate donors) of Ragogna et al., ${ }^{41,42}$ Jones et al., ${ }^{43}$ Dehnicke et al. ${ }^{44}$ and S. Schulz et $a l .{ }^{45}$ which are described as base stabilized dihalopnictanes. In accord with this concept and the fact, that only the open-chain species 2 a was observed in the solid state, a short N-Sb bond length (N1-Sb1 2.133(4) A, Fig. 6), clearly corresponding to a single bond $\left(\sum r_{\text {cov }}(\mathrm{N}-\mathrm{Sb})\right.$ $2.11 \AA$ ), and a significantly longer $\mathrm{Sb}-\mathrm{N}$ distance, indicating only a secondary interaction (N3-Sb1 2.392(4) A), are observed. Furthermore, the in-plane $\mathrm{Sb}-\mathrm{Cl}(\mathrm{Sb} 1-\mathrm{Cl} 2$ 2.451(2) $\AA$ ) bond is elongated compared to the out-of-plane $\mathrm{Sb}-\mathrm{Cl}$ bond ( $\mathrm{Sb} 1-\mathrm{Cl} 1$ $2.358(2) \AA$ ), as it is found for all these base stabilized pnictogen halides. $\mathrm{NBO}$ analyses $(\mathrm{NBO}=\text { natural bond orbital })^{46,47}$ indicate the donation of electron density from the lone pair (LP) located at the imino-N2 atom into the in-plane antibonding $\sum^{*}(\mathrm{Sb}-\mathrm{Cl} 2)$ orbital. $^{40}$ In addition, Menshutkin type (dispersion) interactions between one mesityl group of the terphenyl substituent with the $\mathrm{Sb}$ atom is observed, a common feature of such complexes.

\section{Halide abstraction in 2}

Ring closure in 2 a was easily achieved by addition of a Lewis acid such as $\mathrm{GaCl}_{3}$ via halide abstraction (Fig. 7), affording the cyclic red cationic species $\left(3, \delta\left({ }^{31} \mathrm{P}\right) 374\right.$ ppm, Fig. 6 right $)$ and the $\mathrm{GaCl}_{4}{ }^{-}$ion. The formal charge in 3 is located on the dicoordinated $\mathrm{P}$ atom, hence it will subsequently be denoted as the phosphenium cation, even though the NBO charges indicate stronger charge localization on $\mathrm{Sb}$ than on $\mathrm{P}$ $(\mathrm{Sb}+1.61, \mathrm{P}+1.36 e)$. The large positive charge at the $\mathrm{Sb}$ center mainly arises from strongly polarized $\mathrm{Sb}-\mathrm{N} \sigma$-bonds. Interest-

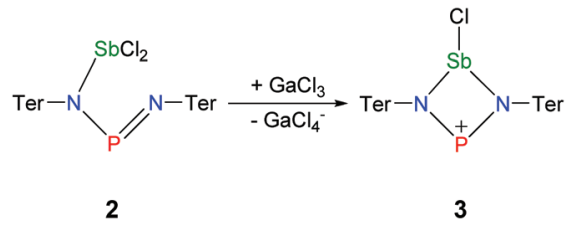

Fig. 7 Ring closure in 2 by halide abstraction affording 3 .

ingly, upon halide abstraction the phosphenium cation is formed rather than the stibenium cation. Also there is no exchange of the $\mathrm{Cl}^{-}$ion between the $\mathrm{P}$ and $\mathrm{Sb}$ atoms of the four-membered ring in solution, which can be observed on the NMR time scale, in accord with computation indicating that the $\mathrm{P}^{+}$centred species is considerably favoured over the $\mathrm{Sb}^{+}$ centred ion by $59.3 \mathrm{~kJ} \mathrm{~mol}^{-1}$. The hypothetical stibenium cation $[\mathrm{ClP}(\mu-\mathrm{NTer}) \mathrm{Sb}]^{+}$, that could result from $\mathrm{Cl}$ shifting from $\mathrm{Sb}$ to $\mathrm{P}$, would have been expected to exhibit green colour ${ }^{48,49}$ (see computations in the ESI + ). The $\mathrm{P}^{+}$center in $[\mathrm{ClSb}(\mu$-NTer)$\mathrm{P}]^{+}$can be better stabilized by delocalization of the nitrogen lone pairs (LP) into the empty p atomic orbitals (AO) of the $\mathrm{P}^{+}$ ion than the $\mathrm{Sb}^{+}$center in hypothetical $[\mathrm{ClP}(\mu-\mathrm{NTer}) \mathrm{Sb}]^{+}$due to the relative orbital mismatch for the donation of an $\mathrm{N}$ lone pair into a $3 \mathrm{p}(\mathrm{P})$ or $5 \mathrm{p}(\mathrm{Sb})$ acceptor orbital in accordance with $\mathrm{NBO}$ analysis data. This formal $\mathrm{p}-\mathrm{LP}(\mathrm{N}) \rightarrow \mathrm{p}-\mathrm{AO}(\mathrm{P})$ hyperconjugation accounts for a significant $\pi$-bond character along the $\mathrm{N}-\mathrm{P}-\mathrm{N}$ unit (see below). Thus both $\mathrm{P}-\mathrm{N}$ distances are rather short and display a double bond character (P1-N2 1.625(3), P1-N1 1.643(4) ̊, $c f$. $\left.\sum r_{\text {cov }}(\mathrm{N}-\mathrm{P}) 1.82 \AA\right),{ }^{38,49}$ while the $\mathrm{Sb}-\mathrm{N}$ distances correspond well with single bonds (Sb1-N1 2.136(3), Sb1-N2 2.171(3), $\left.\sum r_{\text {cov }}(\mathrm{N}-\mathrm{Sb}) 2.11 \AA\right)$.

\section{Reduction of 2}

Reduction of the yellow dichlorostibane 2 was studied using different reducing agents such as $\mathrm{Mg}$ in thf (Fig. 8 and 9) and $\mathrm{KC}_{8}$ (Fig. 10 and 11) in benzene at ambient temperature. Both reactions are rather slow and need ambient temperature. Treatment of 2 with magnesium turnings in thf led to a species, which was first characterized by a singlet ${ }^{31} \mathrm{P}$ NMR resonance at 351 ppm (4, Fig. 9) indicating a di-coordinated phosphorus atom. Interestingly, only a minuscule change of the yellow

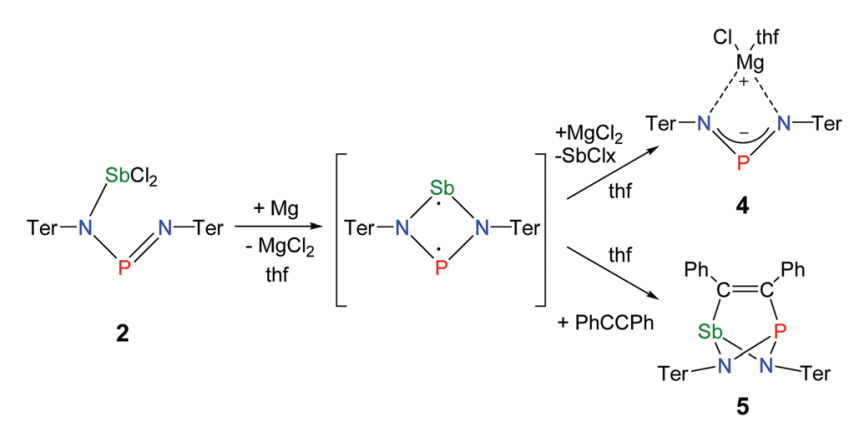

Fig. 8 Reduction of 2 with magnesium and trapping of the transient biradicaloid. 

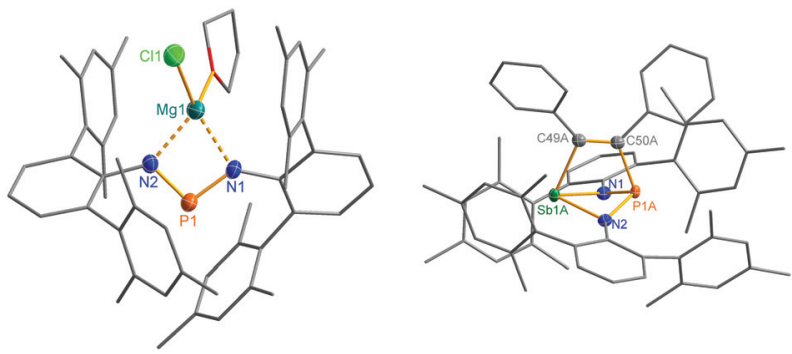

Fig. 9 Molecular structures of 4 and 5. Thermal ellipsoids are drawn at $50 \%$ probability (173 K). Selected bond lengths [Å] and angles [ $\left.{ }^{\circ}\right]$ : 4: P1N2 1.607(2), P1-N1 1.615(2), Cl1-Mg1 2.269(2), Mg1-N1 2.102(2), Mg1N2 2.088(2), N2-P1-N1 98.3(2). 5: Sb1A-C49A 2.228(8), Sb1A-P1A 2.804(2), P1A-C50A 1.947(8), C49A-C50A 1.337(6), C50A-C49A-Sb1A 107.7(4), C49A-C50A-P1A 113.3(4).

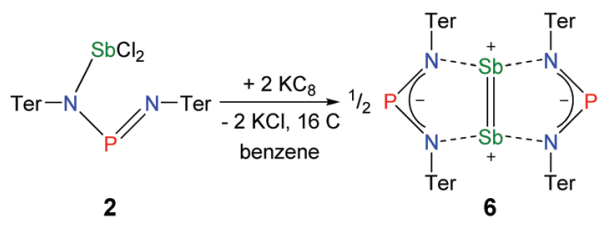

Fig. 10 Reduction of 2 in a non-polar solvent affords 6.

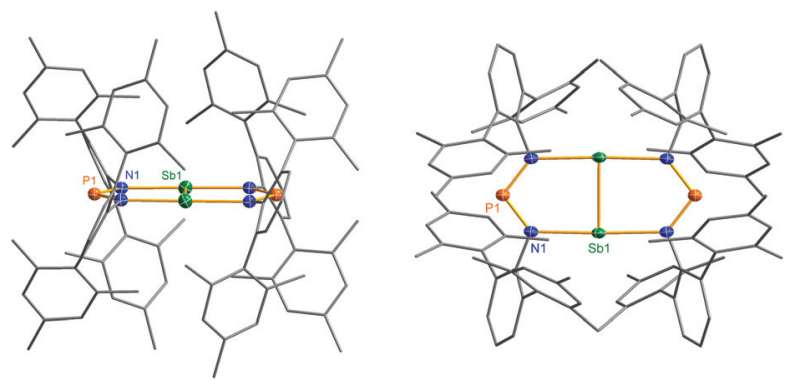

Fig. 11 Molecular structure of 6 (left view: along the Sb-Sb bond, right: topview). Thermal ellipsoids are drawn at $50 \%$ probability (173 K). Selected bond lengths [Å] and angles [ ${ }^{\circ}$ ]: 6: Sb1-Sb1' 2.6438(4), Sb1-N1 2.372(2), P1-N1 1.613(2), N1-Sb1-N1" 177.81(9), N1-Sb1-Sb1' 88.91(4), N1-P1-N1"' 104.6(2).

colour was observed. Single crystal X-ray structure elucidation unequivocally revealed the presence of a magnesium salt of the bis(terphenylimino)-phosphide anion (4). Remarkably, there is quite a significant difference in the ${ }^{31} \mathrm{P}$ NMR shifts when the cation is changed from potassium as in 1 $\left(\mathrm{K}\left[(\mathrm{TerN})_{2} \mathrm{P}\right], \delta\left({ }^{31} \mathrm{P}\right)=322-324 \mathrm{ppm}\right.$ for different solvates $)$ to magnesium in $4\left(\mathrm{MgCl}\left[(\mathrm{TerN})_{2} \mathrm{P}\right] \cdot\right.$ thf, $\left.\delta\left({ }^{31} \mathrm{P}\right)=351 \mathrm{ppm}\right)$ or lithium $\left(\operatorname{Li}\left[(\operatorname{TerN})_{2} \mathrm{P}\right]: 350 \mathrm{ppm}, c f\right.$. ESI $\left.4.1 .+\right)$. This effect can be rationalized by consideration of the hardness (in the sense of the hard-and-soft-acid and base concept) and different cation radii $\left(\mathrm{Li}^{+}: 0.73, \mathrm{Mg}^{2+}: 0.71\right.$ and $\mathrm{K}^{+}: 1.51 \AA$ for the coordination number four). $\mathrm{Li}^{+}$and $\mathrm{Mg}(\mathrm{Cl})^{+}$feature a small but very similar ion radius and thus a stronger downfield shift. The $\mathrm{K}^{+}$ion is considerably larger, hence the cation-anion separation is larger and the charge transfer is of lesser extent as confirmed by NBO analyses (NBO charge K 0.90675; Li 0.82680; second order perturbation theory analysis, maximal contribution: $\mathrm{N}-\mathrm{K}$ 3, N-Li $13 \mathrm{kcal} \mathrm{mol}^{-1}$ ). ${ }^{40}$ From these data it can be concluded, that strongly interacting ion pairs (with a larger charge transfer) display a ${ }^{31} \mathrm{P}$ NMR shift for $\left[(\operatorname{TerN})_{2} \mathrm{P}\right]^{-}$around $350 \mathrm{ppm}$, while for weakly interacting ion pairs this value is shifted to higher field (320-300 ppm).

To prove the intermediate formation of a biradicaloid species $\left[\mathrm{P}(\mu-\mathrm{NTer})_{2} \mathrm{Sb}\right]$ as postulated in Fig. 8, trapping experiments were carried out. Indeed, trapping of the intermediately formed biradicaloid $\left[\mathrm{P}(\mu-\mathrm{NTer})_{2} \mathrm{Sb}\right]$ was possible by addition of a suitable alkyne, e.g. diphenylacetylene, affording the [2.1.1]bicyclic species 5 (Fig. 9 right) in good yield (40\%) as a yellow crystalline substance. The ${ }^{31} \mathrm{P}$ and ${ }^{13} \mathrm{C}$ NMR data as well as the single crystal X-ray data (Fig. 9 right) confirmed the structure of $5\left(\delta\left({ }^{31} \mathrm{P}\right)=219.0, \delta\left({ }^{13} \mathrm{C}\right)=183.95,181.84 \mathrm{ppm}\right)$ in accord with the experimental data observed for [(TerNPCPh $\left.)_{2}\right]\left(\delta\left({ }^{31} \mathrm{P}\right)=\right.$ $\left.246.2, \delta\left({ }^{13} \mathrm{C}\right)=171.09 \mathrm{ppm}\right) .{ }^{50}$ Interestingly, here the resonances for the bridging $\mathrm{C}$ atoms of the former alkyne were observed as doublets due to coupling with only one $\mathrm{P}$ nucleus $\left({ }^{2} J_{\mathrm{C} 49-\mathrm{P}}=6.6,{ }^{1} J_{\mathrm{C} 50-\mathrm{P}}=54 \mathrm{~Hz}, c f\right.$. doublet of doublets, $J_{\mathrm{CP}}=50$, $8.5 \mathrm{~Hz}$ in $\left.\left[(\text { TerNPCPh })_{2}\right]\right)$. The bicyclic trapping product 5 features a strained and distorted [2.1.1] heterobicycle as the central structural motif. The Sb-P distance is considerably longer than expected for a single bond (Sb1-P1 2.804(2), $\sum r_{\text {cov }}(\mathrm{N}-\mathrm{Sb}) 2.51 \AA$, Fig. 9). Both the $\mathrm{Sb}-\mathrm{C}$ and the $\mathrm{P}-\mathrm{C}$ bonds are elongated with respect to the sum of covalent radii (Sb1C49 2.228(8), $\sum r_{\text {cov }}(\mathrm{Sb}-\mathrm{C}) 2.15$; P1-C50 1.947(8), $\sum r_{\text {cov }}(\mathrm{P}-\mathrm{C})$ $1.86 \AA$ ). In contrast, the $\mathrm{C}-\mathrm{C}$ distance clearly corresponds to a double bond (C49-C50 1.337(6), $\sum r_{\text {cov }}(\mathrm{C}=\mathrm{C}) 1.34 \AA$ ) ) manifesting the addition of the triple bond of diphenylacetylene in 5.

The solvent clearly influences the reduction process, since the obtained product 4 contains coordinated solvent molecules. To avoid the formation of decomposition product $\mathbf{4}$, the reduction was carried out with $\mathrm{KC}_{8}$ in benzene, which is a less coordinating solvent (Fig. 10). After addition of two equivalents of $\mathrm{KC}_{8}$ to a solution of 2 in benzene the colour changed to dark green after five minutes often indicating the formation of a distibene intermediate. ${ }^{51-58}$ Finally, within the course of three hours the color of the reaction mixture turned orange. After filtration and concentration orange block-shaped crystals could be isolated in moderate yield (22\%). Surprisingly, instead of the expected biradicaloid $\left[\mathrm{P}(\mu-\mathrm{NTer})_{2} \mathrm{Sb}\right]$, single crystal X-ray analysis revealed the formation of an eight-membered heterocycle of the type $\left[\mathrm{Sb}_{2}-\left\{\mu-(\mathrm{TerN})_{2} \mathrm{P}\right\}_{2}\right]\left(\mathbf{6}, \delta\left({ }^{31} \mathrm{P}\right)\right.$ 325.7 ppm, Fig. 11) with a strong $\mathrm{Sb}-\mathrm{Sb}$ bond. Presumably, the green color of the reaction mixture at the beginning arises from the intermediate formation of blue-colored biradicoid $\left[\mathrm{P}(\mu-\mathrm{NTer})_{2} \mathrm{Sb}\right]\left(c f .\left[\mathrm{P}(\mu-\mathrm{NTer})_{2} \mathrm{As}\right]\right.$ is violet $)$ which isomerizes to give orange $\left[\mathrm{Sb}_{2}-\left\{\mu-(\mathrm{TerN})_{2} \mathrm{P}\right\}_{2}\right] \mathbf{6}$, in accord with TD-DFT computation of the biradicaloid ( $\mathrm{TD}=$ time dependent, see the ESI +$)^{40}$ In contrast to biradicoid $\left[\mathrm{E}(\mu \text {-NTer })_{2} \mathrm{E}\right](\mathrm{E}=\mathrm{P}, \mathrm{As})$, which does not dimerize, biradicaloid $\left[\mathrm{P}(\mu-\mathrm{NTer})_{2} \mathrm{Sb}\right]$ dimerizes along the $\mathrm{Sb}$ atoms to give 6 rather than forming a 
$\mathrm{E}_{4} \mathrm{~N}_{4}$ cage compound as illustrated in Fig. 1 if smaller substituents are utilized. The result is that compound $\mathbf{6}$ is devoid of biradicaloid character. Notably, for the phenyl substituted model compound $\mathbf{6 M}$, all possible cage compounds are thermodynamically more favoured compared to the eightmembered heterocyclic isomer (ca. 35-79 $\mathrm{kJ} \mathrm{mol}^{-1}$, see the ESI $\$)$. This situation changes dramatically when the terphenyl substituted experimentally observed compound 6 is considered. In this case, the cage compounds do not represent a minimum on the PES anymore. Obviously, the folding about the $\mathrm{Sb}-\mathrm{Sb}$ axis, which would lead to the formation of $\alpha$-cage compound 6, is hindered for steric reasons. Bulkier substituents may cause stabilization of the monomeric stiba-phosphadiazanediyl and prevent dimerization. It is worth mentioning that in an attempt to obtain the putative intermediate $\left[\left(\mathrm{Ter}_{2} \mathrm{~N}_{2} \mathrm{PSbCl}\right)_{2}\right]$ by reduction with one equivalent of $\mathrm{KC}_{8}$, only the unreacted starting material and 6 were isolated. ${ }^{55}$

\section{Structure and bonding of 6}

Heterocycle 6 crystallizes in the orthorhombic space group Pnnn with only one quarter of the compound in the asymmetric unit (Fig. 11). The most prominent structural feature is the highly symmetric, planar eight-membered $\mathrm{N}_{4} \mathrm{P}_{2} \mathrm{Sb}_{2}$ heterocycle featuring a very short $\mathrm{Sb}-\mathrm{Sb}$ bond length of 2.6438(4) $\AA$ (cf. $\quad \mathrm{Tbt}_{2} \mathrm{Sb}_{2}$ 2.642(1), $\mathrm{Ter}_{2} \mathrm{Sb}_{2}$ 2.6558(5), $\left[\mathrm{Ar}^{*} \mathrm{~N}\left(\mathrm{Si}^{\mathrm{i}} \mathrm{Pr}_{3}\right)\right]_{2} \mathrm{Sb}_{2}$ 2.7104(5), $\quad \mathrm{Ar}^{*}=$ 2,6-bis(diphenylmethyl)-4-isopropylphenyl $)^{52,55-60}$ displaying a considerable degree of $\pi$-bonding (cf. $\sum r_{\text {cov }}(\mathrm{Sb}-\mathrm{Sb})=2.8$ vs. $\left.\sum r_{\text {cov }}(\mathrm{Sb}=\mathrm{Sb})=2.66 \AA\right) .{ }^{59}$ Hence, the eight-membered heterocycle can also be considered as two condensed five-membered rings. The $\mathrm{Sb}-\mathrm{N}$ bond lengths in 6 amount to $2.372(2) \AA$, which is considerably larger than the sum of covalent radii $\left(\sum r_{\text {cov }}(\mathrm{Sb}-\mathrm{N})=2.11 \AA\right) .{ }^{59}$ Moreover, the short $\mathrm{P}-\mathrm{N}$ distances of 1.613(2) $\AA$ are in the typical range of PN double bonds $\left(\sum r_{\text {cov }}(\mathrm{P}=\mathrm{N})=1.62 \AA\right) .{ }^{59}$ Therefore, it can be deduced that the symmetrically bridging NPN ligand retains its anionic nature in the bridging mode, as indicated by these phosphorus-nitrogen bond lengths, which is similar to analogous structures with $\mu-N, N^{\prime}$ bridging complexes ( $c f$. averaged $\mathrm{P}-\mathrm{N}$ values $1.601(2)$ in $\mathbf{1}, 1.611 \AA$ in 4). The molecular structure of heterocycle 6 is reminiscent to the $(\mathrm{NCN})_{2} \mathrm{P}_{2}$ scaffold of $\left[\mathrm{P}_{2}\{\mu \text {-(MesN })_{2} \mathrm{CNMes}_{2}\right] .^{42,61}$ However, unlike the planar $\mathrm{N}_{4} \mathrm{P}_{2} \mathrm{Sb}_{2}$ bicyclic fragment in $\mathbf{6}$, the $(\mathrm{NCN})_{2} \mathrm{P}_{2}$ scaffold has a puckered arrangement of the two five-membered $\mathrm{P}_{2} \mathrm{~N}_{2} \mathrm{C}$ rings, where the two planes are $100.4^{\circ}$ to each other (Fig. 4). ${ }^{42,61}$ Additionally, the molecular geometry about the phosphorus atoms is trigonal pyramidal and the $\mathrm{P}-\mathrm{P}$ distances are in the range of typical $\mathrm{P}-\mathrm{P}$ single bonds. Recently, Jones et al. reported on base-stabilized diarsenes $\left[\mathrm{As}_{2}-\left\{\mu-(\mathrm{ArN})_{2}-\mathrm{CR}\right\}_{2}\right]$ (Ar $=2$,6-diisopropyl-phenyl, $\left.\mathrm{R}=\mathrm{N}\left({ }^{c} \mathrm{Hex}\right)_{2}, \mathrm{~N}\left({ }^{\mathrm{i}} \mathrm{Pr}\right)_{2},{ }^{t} \mathrm{Bu}\right)^{43}$ displaying also a planar structure of the central structural motif along with a $\mathrm{As}=\mathrm{As}$ double bond similar to the situation found in 6 (Fig. 10). It is interesting to note that the isovalence-electronic triazenide species, $\left[\mathrm{N}(\mu \text {-NTer })_{2} \mathrm{Sb}\right]{ }^{62}$ exists as a monomeric compound and does not dimerize to form the distibenium bicyclic species.
According to DFT calculations, ${ }^{40}$ compound 6 possesses a closed shell singlet ground state, hence it does not exhibit the typical high reactivity of biradicaloids, e.g. it does not react with small molecules as alkynes, phosphaalkynes, isonitriles or diphenyldiazene. In the ${ }^{31} \mathrm{P}$ NMR spectrum, a singlet resonance at $325.7 \mathrm{ppm}$ is observed for $\mathbf{6}$, which is very similar to the value found for the "free" solvated $\left[(\operatorname{TerN})_{2} \mathrm{P}\right]^{-}$ion as in the potassium salt 1 (322-324 ppm, vide supra), also indicating the ionic nature of the interaction between the $\left[(\operatorname{TerN})_{2} \mathrm{P}\right]^{-}$ and $\left[\mathrm{Sb}_{2}\right]^{2+}$ moieties. To gain further insight into the bonding situation of $6, \mathrm{MO}$ ( $\mathrm{MO}=$ molecular orbital), NBO and ELF (electron localization function) ${ }^{63-65}$ computations were carried out. Analysis of the frontier orbitals supports the existence of a highly localized $\mathrm{Sb}=\mathrm{Sb}$ double bond, as illustrated by the HOMO-1 (Fig. 12, HOMO-1 $\pi$ bond, HOMO-2 $\sigma$ bond, HOMO $=$ highest occupied molecular orbital). The LUMO (lowest unoccupied molecular orbital) represents the antibonding counterpart, thus a $\pi$ bond order of one can be considered. While the HOMO is NPN ligand centered, HOMO-12 features large coefficients for the lone pairs at the $\mathrm{Sb}$ atoms, which possess considerable s character.

In accord with this MO picture, NBO analyses find as the best Lewis representation a $\left[\mathrm{Sb}_{2}\right]^{2+}$ ion bearing a double bond that interacts with two $\left[(\text { TerN })_{2} \mathrm{P}\right]^{-}$ions (Fig. 10). For the $\mathrm{Sb}=\mathrm{Sb}$ double bond, there are two contributions, a $\sigma$ and a $\pi$ bond, both being mainly formed by interactions of $\mathrm{p}$ atomic

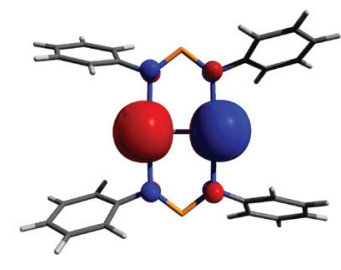

LUMO

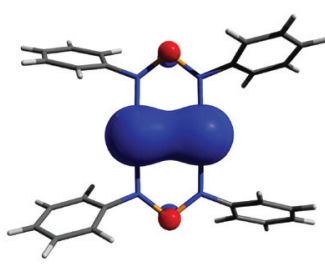

HOMO-1

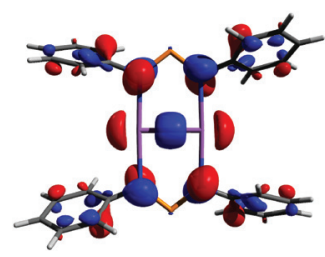

HOMO-10

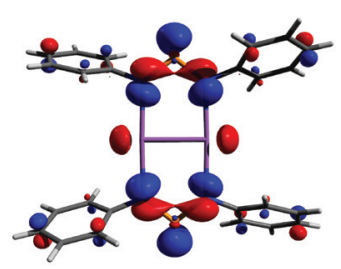

HOMO

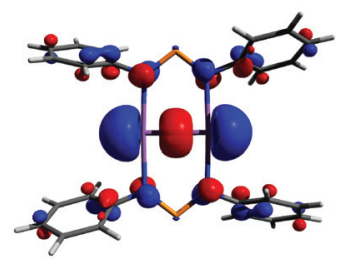

HOMO-2

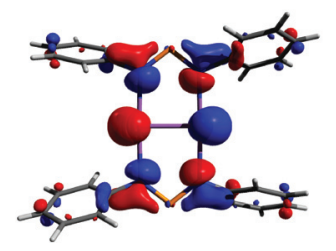

HOMO-12
Fig. 12 Selected Kohn-Sham orbitals of 6 
orbitals located at both $\mathrm{Sb}$ centres. Additionally, a lone pair predominantly carrying s-character is located on both $\mathrm{Sb}$ atoms. However, there are a strong donor-acceptor interactions $(\mathrm{LP}(\mathrm{N}) \rightarrow \mathrm{p}-\mathrm{AO}(\mathrm{Sb})$ hyperconjugation) between the anionic NPN ligands and the $\left[\mathrm{Sb}_{2}\right]^{2+}$ cation, accompanied by a considerable charge transfer. The computed NLMO/NPA bond (NLMO = natural molecular orbital, NPA natural population analysis) indices amount to 0.99 for the $\mathrm{Sb}-\mathrm{Sb} \sigma$-bond and 0.94 for the $\pi$-bond, while only a value of 0.17 was found for each $\mathrm{Sb}-\mathrm{N}$ bond. The total valency for each antimony was estimated to be 2.29 in accord with the picture of a base stabilized $\left[\mathrm{Sb}_{2}\right]^{2+}$ ion. The NBO data are in good agreement with the values reported by Jones et al. for the base-stabilized diarsene $\left[\mathrm{As}_{2}-\left\{\mu-(\mathrm{ArN})_{2}-\mathrm{CR}\right\}_{2}\right] \cdot{ }^{43}$ However, the electronic stabilization invoked by the amidinate or guanidate ligand was not sufficient to enable the preparation of the corresponding distibene. Base stabilized antimony cations were the focus of recent research. ${ }^{66}$ For instance, stibinostibonium ions have been published by Breunig et al. $\left(\left[\mathrm{Me}_{3} \mathrm{Sb}-\mathrm{SbMe}_{2}\right]^{2+}\right)^{67}$ and our group $\left(\left[\left(\mathrm{Me}_{3} \mathrm{Sb}\right)_{2} \mathrm{SbMe}\right]^{2+}\right)^{68,69}$ as well as a series of different interpnictogen $\mathrm{Sb}$ cations by Burford et al. (e.g. $\left.\left[\mathrm{Sb}_{4}\left(\mathrm{PMe}_{3}\right)_{4}\right]^{4+}\right) .^{66,70-73}$

The ELF of 6 also indicates the presence of a double bond as depicted in Fig. $13 .{ }^{63-65,74-76}$ In 6 , the $\mathrm{Sb}=\mathrm{Sb}$ double bond domain is characterized by a dumb-bell shaped region of localized electrons $(\mathrm{ELF}=0.75)$ in accord with the description of a classical double bond in a planar environment (e.g. in ethylene $\mathrm{C}_{2} \mathrm{H}_{4}$ ) and in contrast to the situation of non-classical double
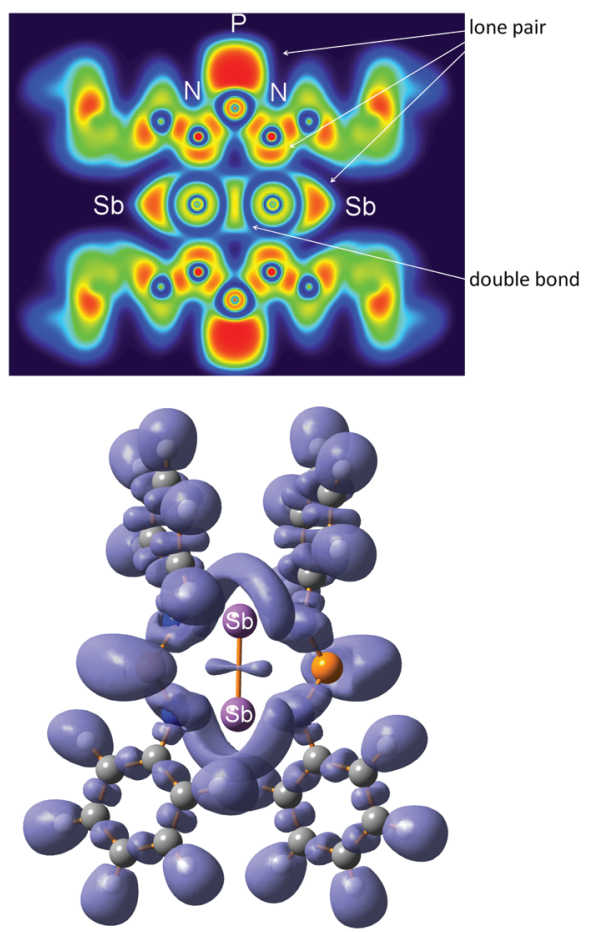

Fig. 13 Top: two-dimensional (2D) cross section through the molecule in 6. Bottom: 3D representation of the ELF at 0.75 . bonds (slipped double bonds) usually found between heavy main group elements. ${ }^{63,74}$ However, as pointed out by Grützmacher and Fässler dipnictogens of the type $\mathrm{RE}=\mathrm{ER}(\mathrm{E}=$ $\mathrm{N}-\mathrm{Bi}$ ) fall within the category of classical double bonds displaying a strong resemblance to the situation in ethylene. ${ }^{74}$

Finally, we want to address the question why dimerization occurred via $\mathrm{Sb}-\mathrm{Sb}$ linkage and ring opening in the biradicaloid intermediate $\left[\mathrm{P}(\mu-\mathrm{NTer})_{2} \mathrm{Sb}\right]$ rather than cage formation (vide supra). For this reason, we computed the biradical character $\beta\left(\beta=c_{2}{ }^{2} /\left(c_{1}{ }^{2}+c_{2}{ }^{2}\right)\right.$ utilizing the method reported by Miliordios et $a l^{77}$ The coefficients $c_{1}$ and $c_{2}$ were obtained from the complete active space self-consistent field (CASSCF $(2,2))$ level of theory. According to these computations, the biradical character of $\left[\mathrm{P}(\mu \text {-NTer })_{2} \mathrm{Sb}\right]$ amounts to only $8 \%$, which is rather small for dipnictadiazanediyls $\left(c f .25-33 \%\right.$ for $[\mathrm{E}(\mu-\mathrm{NTer})]_{2}, \mathrm{E}=$ $\mathrm{P}$, As, $c f$. ESI 4.4.\$). ${ }^{62}$ Nevertheless, biradicaloid reactivity was experimentally observed for $\left[\mathrm{P}(\mu-\mathrm{NTer})_{2} \mathrm{Sb}\right]$ ("monomeric" 6). In contrast, isovalence-electronic $\left[\mathrm{N}(\mu-\mathrm{NTer})_{2} \mathrm{E}\right](\mathrm{E}=\mathrm{P}, \mathrm{As}, \mathrm{Sb})$ do not activate small molecules, e.g. alkynes, to form [2.1.1]bicycles, but possess similar $\beta$ values compared to $\left[\mathrm{P}(\mu-\mathrm{NTer})_{2} \mathrm{Sb}\right]\left(\left[\mathrm{N}(\mu-\mathrm{NTer})_{2} \mathrm{E}\right], \beta: \mathrm{E}=\mathrm{P} 15 \%, \mathrm{As} 10 \%, \mathrm{Sb} 6 \%, \mathrm{Bi}\right.$ $0 \%)$. Thus the success of the trapping reaction of $[\mathrm{P}(\mu-$ $\left.\mathrm{NTer})_{2} \mathrm{Sb}\right]$ with alkynes to form [2.1.1] bicycle 5 was unexpected (see Fig. 9), as well as the formal dimerization to 6 if no trapping reagent was available. We had expected a kinetically stabilized $\left[\mathrm{P}(\mu-\mathrm{NTer})_{2} \mathrm{Sb}\right]$ biradical as it was the case for $[\mathrm{E}(\mu-$ $\left.\mathrm{NTer})_{2} \mathrm{E}\right](\mathrm{E}=\mathrm{P}, \mathrm{As})$ or $\left[\mathrm{N}(\mu-\mathrm{NTer})_{2} \mathrm{E}\right](\mathrm{E}=\mathrm{P}-\mathrm{Sb})$. However, compared to the lighter congeners $\left[\mathrm{P}(\mu-\mathrm{NTer})_{2} \mathrm{Sb}\right]$ features rather long $\mathrm{N}-\mathrm{Sb}$ bonds and acute $\mathrm{N}-\mathrm{Sb}-\mathrm{N}$ angles due to predominantly ionic bonding thus providing less steric protection around the antimony and allowing dimerization. Interestingly, for 6 the computed biradical character amounts to zero and therefore, a conventional closed-shell species is anticipated. This confirms the observation, that no activation of small molecules bearing multiple bonds was achieved, even though steric congestion contributes to the inertness of $\mathbf{6}$ as well.

\section{Conclusions}

In conclusion, the initially targeted biradicaloid $\left[\mathrm{P}(\mu-\mathrm{NTer})_{2} \mathrm{Sb}\right]$ remains elusive, its existence as transient species, however, could be corroborated by trapping with diphenylacetylene forming a [2.1.1]bicycle. In the absence of a trapping reagent, $\left[\mathrm{P}(\mu \text {-NTer })_{2} \mathrm{Sb}\right]$ dimerizes via $\mathrm{Sb}-\mathrm{Sb}$ double bond formation affording a novel planar eight-membered $\mathrm{N}_{4} \mathrm{P}_{2} \mathrm{Sb}_{2}$ heterocycle (6). Due to the highly polar $\mathrm{Sb}-\mathrm{N}$ bond situation, the formal dimer 6 might also be regarded as a donor stabilized $[\mathrm{Sb}=\mathrm{Sb}]^{2+}$ ion in accord with MO, NBO and ELF considerations.

\section{Experimental section}

All manipulations were carried out under oxygen- and moisture-free conditions under argon using standard Schlenk or 
drybox techniques. The preparation of 1 was reported earlier. ${ }^{38}$ Full experimental and computational data are available in the ESI.†

\section{Synthesis of 2}

$188 \mathrm{mg}$ of $\mathrm{K}\left[(\mathrm{TerN})_{2} \mathrm{P}\right](0.259 \mathrm{mmol})$ were dissolved in $5 \mathrm{ml}$ of toluene. To the yellow solution, a solution of $60 \mathrm{mg} \mathrm{SbCl}_{3}$ $(0.263 \mathrm{mml})$ in $3 \mathrm{ml}$ toluene was added. The solution became turbid after a few minutes and was stirred for 3 hours to ensure completion of the reaction. The solution was filtered over a sinter padded with kieselguhr (Celite, G4) and the residue was washed with further $3 \mathrm{ml}$ of toluene. The filtrate was concentrated to incipient crystallization $(1 \mathrm{ml})$ and left undisturbed overnight at $4{ }^{\circ} \mathrm{C}$, resulting in the deposition of yellow crystals. The mother liquor was removed via syringe and the crystals were dried in vacuo, yielding $163 \mathrm{mg}(0.186 \mathrm{mmol}$, $72 \%$ ) of the product.

Mp: $215{ }^{\circ} \mathrm{C}$ (dec.). EA for $\mathrm{C}_{48} \mathrm{H}_{50} \mathrm{~N}_{2} \mathrm{PSbCl}_{2}$ found (calc.): C 65.03 (65.62), H 5.78 (5.74), N 3.26 (3.19). ${ }^{1}$ H NMR (298 K, $\left.\mathrm{C}_{6} \mathrm{D}_{6}, 250.1 \mathrm{MHz}\right): 2.08$ (s, $\left.24 \mathrm{H}, o-\mathrm{CH}_{3}\right), 2.24\left(\mathrm{~s}, 12 \mathrm{H}, p-\mathrm{CH}_{3}\right)$, 6.81 (s, $\left.8 \mathrm{H}, m-\mathrm{CH}_{\mathrm{Mes}}\right), 6.83-6.91(\mathrm{~m}, 6 \mathrm{H}, \mathrm{CH}) .{ }^{31} \mathbf{P}$ NMR (298 K, $\left.\mathrm{C}_{6} \mathrm{D}_{6}, 121.5 \mathrm{MHz}\right): 331.5$ (br s).

\section{Synthesis of 3}

To a solution of $\left[\mathrm{Ter}_{2} \mathrm{~N}_{2} \mathrm{PSbCl}_{2}\right](191 \mathrm{mg}, 0.217 \mathrm{mmol})$ in dichloromethane $(4 \mathrm{ml})$, a solution of $\mathrm{GaCl}_{3}(39 \mathrm{mg}$, $0.221 \mathrm{mmol}$ ) is added dropwise at $-80{ }^{\circ} \mathrm{C}$. The initially yellow solution immediately turns red and is stirred for further 15 minutes at the same temperature before being warmed to $20{ }^{\circ} \mathrm{C}$. The solution is then concentrated until crystallization commences $(0.5 \mathrm{ml})$ and left undisturbed overnight, which leads to the formation of red needle-shaped crystals $(168 \mathrm{mg}$, $0.159 \mathrm{mmol}, 73 \%$ ). Crystals suitable for X-ray structure elucidation were obtained by repeated recrystallization from dichloromethane between $25^{\circ} \mathrm{C}$ and $4{ }^{\circ} \mathrm{C}$.

Mp: $258{ }^{\circ} \mathrm{C}$ (dec.). EA for $\mathrm{C}_{48} \mathrm{H}_{50} \mathrm{~N}_{2} \mathrm{PSbGaCl}_{5}$ found (calc.): C 54.53 (54.66), H 5.48 (4.78), N 2.93 (2.66). ${ }^{1}$ H NMR (298 K, $\left.\mathrm{CD}_{2} \mathrm{Cl}_{2}, 250.1 \mathrm{MHz}\right): 1.90\left(\mathrm{~s}, 24 \mathrm{H}, o-\mathrm{CH}_{3}\right), 2.44(\mathrm{~s}, 12 \mathrm{H}$, $\left.p-\mathrm{CH}_{3}\right), 7.03\left(\mathrm{~d},{ }^{3} J_{\mathrm{HH}}=7.7 \mathrm{~Hz}, 4 \mathrm{H}, m-\mathrm{CH}\right), 7.06(\mathrm{~s}, 8 \mathrm{H}$, $m$-CH $\left.H_{\mathrm{Mes}}\right), 7.28\left(\mathrm{t},{ }^{3} \mathrm{~J}_{\mathrm{HH}}=7.7 \mathrm{~Hz}, 2 \mathrm{H}, p-\mathrm{CH}\right) .{ }^{31} \mathbf{P}$ NMR $(298 \mathrm{~K}$, $\left.\mathrm{CD}_{2} \mathrm{Cl}_{2}, 121.5 \mathrm{MHz}\right): 374.0(\mathrm{~s})$.

\section{Synthesis of 4}

$\left[\mathrm{Ter}_{2} \mathrm{~N}_{2} \mathrm{PSbCl}_{2}\right.$ ] (200 mg, $0.228 \mathrm{mmol}$ ) and magnesium turnings $(80 \mathrm{mg}$ ) were combined in a flask. To this mixture, $10 \mathrm{ml}$ THF was added and the suspension was stirred overnight at ambient temperature with a glass stirring bar. Out of the initially yellow solution a black precipitate was formed. Volatiles were removed in vacuo and the residue was extracted with $10 \mathrm{ml}$ benzene and washed with an additional $3 \mathrm{ml}$ of benzene. The combined filtrate was concentrated to incipient crystallization (approx. $2 \mathrm{ml}$ ) and left undisturbed overnight, resulting in the deposition of light yellow crystals. The supernatant was removed via syringe and the crystals were dried in vacuo (130 mg, $0.159 \mathrm{mmol}, 70 \%)$.
Mp: $110{ }^{\circ} \mathrm{C}$ (dec.). EA for $\mathrm{C}_{52} \mathrm{H}_{58} \mathrm{~N}_{2} \mathrm{PMgClO}$ found (calc.): C 75.92 (76.37), H 7.36 (7.15), N 3.14 (3.43). ${ }^{1}$ H NMR (298 K, $\left.\mathrm{C}_{6} \mathrm{D}_{6}, 250.1 \mathrm{MHz}\right): 1.21\left(\mathrm{~m}, 4 \mathrm{H}, \mathrm{OCH}_{2} \mathrm{CH}_{2}\right), 1.98(\mathrm{~s}, 12 \mathrm{H}$, $\left.o-\mathrm{CH}_{3}\right), 2.03\left(\mathrm{~s}, 12 \mathrm{H}, o-\mathrm{CH}_{3}\right), 2.23\left(\mathrm{~s}, 12 \mathrm{H}, p-\mathrm{CH}_{3}\right), 3.21(\mathrm{~m}$, $\left.4 \mathrm{H}, \mathrm{OCH}_{2} \mathrm{CH}_{2}\right), 6.80-6.89(\mathrm{~m}, 6 \mathrm{H}, m-/ p-\mathrm{CH}), 6.87(\mathrm{~s}, 8 \mathrm{H}$, $\left.m-\mathrm{CH}_{\mathrm{Mes}}\right) \cdot{ }^{31} \mathbf{P}$ NMR $\left(298 \mathrm{~K}, \mathrm{C}_{6} \mathrm{D}_{6}, 121.5 \mathrm{MHz}\right): 351.8$ (s).

\section{Synthesis of 5}

$\left[\mathrm{Ter}_{2} \mathrm{~N}_{2} \mathrm{PSbCl}_{2}\right]$ (180 mg, $\left.0.205 \mathrm{mmol}\right)$, diphenylacetylene (53 mg) and magnesium turnings $(80 \mathrm{mg}$ ) were combined in a flask. To the mixture, $10 \mathrm{ml}$ thf was added. After stirring with a glass-covered stirring bar, the initially yellow solution turned orange and a black precipitate formed. Volatiles were removed in vacuo and the residue was extracted with $5 \mathrm{ml}$ benzene and then washed with another portion of $3 \mathrm{ml}$ of benzene. The extract was then concentrated to incipient crystallization and left undisturbed overnight, affording orange crystals. The mother liquor was removed via syringe and the crystals were dried in vacuo ( $82 \mathrm{mg}, 0.083 \mathrm{mmol}, 40 \%$ ).

Mp. $231{ }^{\circ} \mathrm{C}$ (dec.). EA found (calc.): C 68.93 (69.39), H 6.00 (5.64), N 2.86 (2.61). ${ }^{1} \mathrm{H}$ NMR (298 K, $\left.\mathrm{C}_{6} \mathrm{D}_{6}, 250.1 \mathrm{MHz}\right): 2.05$ $\left(\mathrm{s}, 12 \mathrm{H}, o-\mathrm{CH}_{3}\right), 2.09\left(\mathrm{~s}, 12 \mathrm{H}, o-\mathrm{CH}_{3}\right), 2.20\left(\mathrm{~s}, 12 \mathrm{H}, p-\mathrm{CH}_{3}\right)$, $6.54\left(\mathrm{~s}, 8 \mathrm{H}, \mathrm{CH}_{\mathrm{Mes}}\right), 6.68(\mathrm{~s}, 6 \mathrm{H}, m-/ p-\mathrm{CH}), 6.82-7.23(\mathrm{~m}, 10 \mathrm{H}$, $\left.\mathrm{CH}_{\mathrm{Ph}}\right) .{ }^{31} \mathrm{P}$ NMR $\left(298 \mathrm{~K}, \mathrm{C}_{6} \mathrm{D}_{6}, 121.5 \mathrm{MHz}\right): 219.0$ (s).

\section{Synthesis of 6}

[ $\mathrm{Ter}_{2} \mathrm{~N}_{2} \mathrm{PSbCl}_{2}$ ] (215 mg, $0.245 \mathrm{mmol}$ ) was dissolved in $5 \mathrm{ml}$ of benzene while stirring with a glass stirring bar. To the solution, $\mathrm{KC}_{8}(70 \mathrm{mg}, 0.518 \mathrm{mmol})$ was added. The solution adopted a dark green colour after 5 minutes. To ensure completion of the reaction, the suspension was stirred for 3 hours at ambient temperature. The suspension was filtered over a sinter padded with kieselguhr (Celite) and the residue was washed with another portion of $2 \mathrm{ml}$ of benzene. The combined filtrate was concentrated to incipient crystallization (approx. $1 \mathrm{ml}$ ) and left undisturbed overnight. Orange blockshaped crystals were obtained. The supernatant was removed via syringe and the crystals were dried in vacuo (43 mg, $0.027 \mathrm{mmol}, 22 \%)$.

Mp: $110{ }^{\circ} \mathrm{C}$ (dec.). EA found (calc.): C 70.80 (70.98), H 6.98 (6.76), N 3.48 (3.45). ${ }^{1} \mathrm{H}$ NMR (298 K, $\left.\mathrm{C}_{6} \mathrm{D}_{6}, 250.1 \mathrm{MHz}\right): 2.03$ $\left(\mathrm{s}, 48 \mathrm{H}, o-\mathrm{CH}_{3}\right), 2.25\left(\mathrm{~s}, 24 \mathrm{H}, p-\mathrm{CH}_{3}\right), 6.72\left(\mathrm{~s}, 16 \mathrm{H}, m-\mathrm{CH}_{\mathrm{Mes}}\right)$, 6.80-6.93 (m, $12 \mathrm{H}, m-/ p-\mathrm{CH}) .{ }^{31} \mathbf{P}$ NMR (298 K, $\mathrm{C}_{6} \mathrm{D}_{6}$, 121.5 MHz): $326.0(\mathrm{~s})$.

\section{Acknowledgements}

The authors thank the DFG (SCHU 1170/11-1) for financial support. M.Sc. Jonas Bresien is gratefully acknowledged for setting up and maintaining Gaussian and NBO software on the cluster computer. Dr Dirk Michalik is acknowledged for recording temperature-variable NMR spectra. A.H. thanks the GDCh for financial support. 


\section{Notes and references}

1 A. Michaelis and G. Schroeter, Chem. Ber., 1894, 27, 490497.

2 M. S. Balakrishna, D. J. Eisler and T. Chivers, Chem. Soc. Rev., 2007, 36, 650-664.

3 D. A. DuBois, E. N. Duesler and R. T. Paine, Organometallics, 1983, 2, 1903-1905.

4 D. A. DuBois, E. N. Duesler and R. T. Paine, Organometallics, 1984, 3, 1913-1915.

5 D. A. DuBois, E. N. Duesler and R. T. Paine, Inorg. Chem., 1985, 24, 3-5.

6 D. A. DuBois, E. N. Duesler and R. T. Paine, J. Chem. Soc., Chem. Commun., 1984, 488-489.

7 H. Bladt, S. G. Calera, J. Goodman, R. J. Less, V. Naseri, A. Steiner and D. S. Wright, Chem. Commun., 2009, 66376639.

8 T. Beweries, R. Kuzora, U. Rosenthal, A. Schulz and A. Villinger, Angew. Chem., 2011, 123, 9136-9140, (Angew. Chem., Int. Ed., 2011, 50, 8974-8978).

9 M. Abe, Chem. Rev., 2013, 113, 7011-7088.

10 F. Breher, Coord. Chem. Rev., 2007, 251, 1007-1043.

11 G. He, O. Shynkaruk, M. W. Lui and E. Rivard, Chem. Rev., 2014, 114, 7815-7880.

12 E. Niecke, A. Fuchs, F. Baumeister, M. Nieger and W. W. Schoeller, Angew. Chem., 1995, 107, 640-642, (Angew. Chem., Int. Ed., 1995, 34, 555-557).

13 M. Sebastian, A. Hoskin, M. Nieger, L. Nyulaszi and E. Niecke, Angew. Chem., 2005, 117, 1429-1432, (Angew. Chem., Int. Ed., 1995, 44, 1405-1408).

14 O. Schmidt, A. Fuchs, D. Gudat, M. Nieger, W. Hoffbauer, E. Niecke and W. W. Schoeller, Angew. Chem., 1998, 110, 995-998, (Angew. Chem., Int. Ed., 1998, 37, 949-952).

15 E. Niecke, A. Fuchs, M. Nieger, O. Schmidt and W. W. Schoeller, Angew. Chem., 1999, 111, 3216-3219, (Angew. Chem., Int. Ed., 1999, 38, 3028-3031).

16 M. Blättner, M. Nieger, A. Ruban, W. W. Schoeller and E. Niecke, Angew. Chem., 2000, 112, 2876-2879, (Angew. Chem., Int. Ed., 2000, 39, 2768-2771).

17 M. Sebastian, M. Nieger, D. Szieberth, L. Nyulászi and E. Niecke, Angew. Chem., 2004, 116, 647-651, (Angew. Chem., Int. Ed., 2004, 43, 637-641).

18 S. Ito, M. Kikuchi, H. Sugiyama and M. Yoshifuji, J. Organomet. Chem., 2007, 692, 2761-2767.

19 S. Ito, J. Miura, N. Morita, M. Yoshifuji and A. J. Arduengo, C. R. Chim., 2010, 13, 1180-1184.

20 H. Sugiyama, S. Ito and M. Yoshifuji, Chem. - Eur. J., 2004, 10, 2700-2706.

21 M. Yoshifuji, A. J. Arduengo III, T. A. Konovalova, L. D. Kispert, M. Kikuchi and S. Ito, Chem. Lett., 2006, 35, 1136-1137.

22 S. Ito, M. Kikuchi, J. Miura, N. Morita and M. Yoshifuji, J. Phys. Org. Chem., 2012, 25, 733-737.

23 H. Sugiyama, S. Ito and M. Yoshifuji, Angew. Chem., 2003, 115, 3932-3934, (Angew. Chem., Int. Ed., 2003, 42, 38023804).
24 V. Gandon, J.-B. Bourg, F. S. Tham, W. W. Schoeller and G. Bertrand, Angew. Chem., 2007, 120, 161-165, (Angew. Chem., Int. Ed., 2008, 47, 155-159).

25 J.-B. Bourg, A. Rodriguez, D. Scheschkewitz, H. Gornitzka, D. Bourissou and G. Bertrand, Angew. Chem., 2007, 120, 5843-5847, (Angew. Chem., Int. Ed., 2007, 46, 5741-5745).

26 H. Amii, L. Vranicar, H. Gornitzka, D. Bourissou and G. Bertrand, J. Am. Chem. Soc., 2004, 126, 1344-1345.

27 G. Fuks, N. Saffon, L. Maron, G. Bertrand and D. Bourissou, J. Am. Chem. Soc., 2009, 131, 13681-13689.

28 A. F. Richards, M. Brynda, M. M. Olmstead and P. P. Power, Organometallics, 2004, 23, 2841-2844.

29 C. Schenk, A. Kracke, K. Fink, A. Kubas, W. Klopper, M. Neumaier, H. Schnöckel and A. Schnepf, J. Am. Chem. Soc., 2011, 133, 2518-2524.

30 C. Schrenk, A. Kubas, K. Fink and A. Schnepf, Angew. Chem., 2011, 123, 7411-7415, (Angew. Chem., Int. Ed., 2011, 50, 7273-7277).

31 X. Wang, Y. Peng, M. M. Olmstead, J. C. Fettinger and P. P. Power, J. Am. Chem. Soc., 2009, 131, 14164-14165.

32 P. Henke, T. Pankewitz, W. Klopper, F. Breher and H. Schnöckel, Angew. Chem., 2009, 121, 8285-8290, (Angew. Chem., Int. Ed., 2009, 48, 8141-8145).

33 H. Cox, P. B. Hitchcock, M. F. Lappert and L. J.-M. Pierssens, Angew. Chem., 2004, 116, 4600-4604, (Angew. Chem., Int. Ed., 2004, 43, 4500-4504).

34 K. Takeuchi, M. Ichinohe and A. Sekiguchi, J. Am. Chem. Soc., 2011, 133, 12478-12481.

35 S. H. Zhang, H. W. Xi, K. H. Lim, Q. Meng, M. B. Huang and C. W. So, Chem. - Eur. J., 2012, 18, 4258-4263.

36 H. Sugiyama, S. Ito and M. Yoshifuji, Chem. - Eur. J., 2004, 10, 2700-2706.

37 P. P. Power, Chem. Rev., 2003, 103, 789-810.

38 A. Hinz, A. Schulz and A. Villinger, Angew. Chem., 2014, 127, 678-682, (Angew. Chem., Int. Ed., 2014, 54, 668672).

39 M. J. Frisch, G. W. Trucks, H. B. Schlegel, G. E. Scuseria, M. A. Robb, J. R. Cheeseman, G. Scalmani, V. Barone, B. Mennucci, G. A. Petersson, H. Nakatsuji, M. Caricato, X. Li, H. P. Hratchian, A. F. Izmaylov, J. Bloino, G. Zheng, J. L. Sonnenberg, M. Hada, M. Ehara, K. Toyota, R. Fukuda, J. Hasegawa, M. Ishida, T. Nakajima, Y. Honda, O. Kitao, H. Nakai, T. Vreven, J. A. Montgomery, J. E. Peralta, F. Ogliaro, M. Bearpark, J. J. Heyd, E. Brothers, K. N. Kudin, V. N. Staroverov, R. Kobayashi, J. Normand, K. Raghavachari, A. Rendell, J. C. Burant, S. S. Iyengar, J. Tomasi, M. Cossi, N. Rega, J. M. Millam, M. Klene, J. E. Knox, J. B. Cross, V. Bakken, C. Adamo, J. Jaramillo, R. Gomperts, R. E. Stratmann, O. Yazyev, A. J. Austin, R. Cammi, C. Pomelli, J. W. Ochterski, R. L. Martin, K. Morokuma, V. G. Zakrzewski, G. A. Voth, P. Salvador, J. J. Dannenberg, S. Dapprich, A. D. Daniels, Ö. Farkas, J. B. Foresman, J. V. Ortiz, J. Cioslowski and D. J. Fox, GAUSSIAN 09, Gaussian, Inc., Wallingford CT, 2009.

40 Computations were carried out at the pbe1pbe level of theory utilizing a 6-31G(d,p) basis for $\mathrm{H}, \mathrm{C}, \mathrm{N}, \mathrm{P}$ atoms and 
a relativistic pseudopotential was used for Sb: ECP46MDF 446.

41 A. L. Brazeau, A. S. Nikouline and P. J. Ragogna, Chem. Commun., 2011, 47, 4817-4819.

42 A. L. Brazeau, M. M. Hänninen, H. M. Tuononen, N. D. Jones and P. J. Ragogna, J. Am. Chem. Soc., 2012, 134, 5398-5414.

43 S. P. Green, C. Jones, G. Jin and A. Stasch, Inorg. Chem., 2007, 46, 8-10.

44 C. Ergezinger, F. Weller and K. Dehnicke, Z. Naturforsch., B: Anorg. Chem. Org. Chem., 1988, 43, 1119-1124.

45 B. Lyhs, S. Schulz, U. Westphal, D. Bläser, R. Boese and M. Bolte, Eur. J. Inorg. Chem., 2009, 2009, 2247-2253.

46 E. D. Glendening, C. R. Landis and F. Weinhold, J. Comput. Chem., 2013, 34, 1429-1437.

47 A. E. Reed, L. A. Curtiss and F. Weinhold, Chem. Rev., 1988, 88, 899-926.

48 M. Lehmann, A. Schulz and A. Villinger, Angew. Chem., 2012, 124, 8211-8215, (Angew. Chem., Int. Ed., 2012, 51, 8087-8091).

49 D. Michalik, A. Schulz, A. Villinger and N. Weding, Angew. Chem., 2008, 120, 6565-6568, (Angew. Chem., Int. Ed., 2008, 47, 6465-6468).

50 A. Hinz, R. Kuzora, U. Rosenthal, A. Schulz and A. Villinger, Chem. - Eur. J., 2014, 20, 14659-14673.

51 T. Sasamori, Y. Arai, N. Takeda, R. Okazaki, Y. Furukawa, M. Kimura, S. Nagase and N. Tokitoh, Bull. Chem. Soc. Jpn., 2002, 75, 661-675.

52 N. Tokitoh, Y. Arai, T. Sasamori, R. Okazaki, S. Nagase, H. Uekusa and Y. Ohashi, J. Am. Chem. Soc., 1998, 120, 433-434.

53 T. Sasamori and N. Tokitoh, Dalton Trans., 2008, 13951408.

54 T. Sasamori, N. Takeda and N. Tokitoh, J. Phys. Org. Chem., 2003, 16, 450-462.

55 B. Twamley, C. D. Sofield, M. M. Olmstead and P. P. Power, J. Am. Chem. Soc., 1999, 121, 3357-3367.

56 M. Sakagami, T. Sasamori, H. Sakai, Y. Furukawa and N. Tokitoh, Bull. Chem. Soc. Jpn., 2013, 86, 1132-1143.

57 M. Sakagami, T. Sasamori, H. Sakai, Y. Furukawa and N. Tokitoh, Chem. - Asian J., 2013, 8, 690-693.

58 T. Sasamori, E. Mieda, N. Nagahora, K. Sato, D. Shiomi, T. Takui, Y. Hosoi, Y. Furukawa, N. Takagi, S. Nagase and N. Tokitoh, J. Am. Chem. Soc., 2006, 128, 12582-12588.
59 P. Pyykkö and M. Atsumi, Chem. - Eur. J., 2009, 15, 1277012779.

60 D. Dange, A. Davey, J. A. B. Abdalla, S. Aldridge and C. Jones, Chem. Commun., 2015, 51, 7128-7131.

61 H. W. Roesky, H. Zamankhan, W. S. Sheldrick, A. H. Cowley and S. K. Mehrotra, Inorg. Chem., 1981, 20, 2910-2915.

62 A. Hinz, A. Schulz and A. Villinger, J. Am. Chem. Soc., 2015, 137, 3975-3980.

63 T. E. Fässler and A. Savin, Chemie unserer Zeit, 1997, 31, 110-120.

64 A. Savin, O. Jepsen, J. Flad, O. K. Andersen, H. Preuss and H. G. von Schnering, Angew. Chem., 1992, 104, 186-188, (Angew. Chem., Int. Ed., 1992, 31, 187-188).

65 A. D. Becke and K. E. Edgecombe, J. Chem. Phys., 1990, 92, 5397.

66 A. P. M. Robertson, P. A. Gray and N. Burford, Angew. Chem., 2014, 127, 6162-6182, (Angew. Chem., Int. Ed., 2014, 53, 6050-6069).

67 H. Althaus, H. J. Breunig and E. Lork, Chem. Commun., 1999, 1971-1972.

68 C. Hering, M. Lehmann, A. Schulz and A. Villinger, Inorg. Chem., 2012, 51, 8212-8224.

69 C. Hering, J. Rothe, A. Schulz and A. Villinger, Inorg. Chem., 2013, 52, 7781-7790.

70 S. S. Chitnis, Y. Y. Carpenter, N. Burford, R. McDonald and M. J. Ferguson, Angew. Chem., 2013, 125, 4963-4966, (Angew. Chem., Int. Ed., 2013, 52, 4863-4866).

71 S. S. Chitnis, A. P. M. Robertson, N. Burford, J. J. Weigand and R. Fischer, Chem. Sci., 2015, 6, 2559-2574.

72 E. Conrad, N. Burford, U. Werner-Zwanziger, R. McDonald and M. J. Ferguson, Chem. Commun., 2010, 46, 2465-2467.

73 A. P. M. Robertson, N. Burford, R. McDonald and M. J. Ferguson, Angew. Chem., 2014, 126, 3548-3551, (Angew. Chem., Int. Ed., 2014, 53, 3480-3483).

74 H. Grützmacher and T. Fässler, Chem. - Eur. J., 2000, 6, 2317-2325.

75 A. Savin, R. Nesper, S. Wengert and T. E. Fässler, Angew. Chem., 1997, 125, 1892-1918, (Angew. Chem., Int. Ed., 1997, 36, 1808-1832).

76 H.-J. Flad, F. Schautz, Y. Wang, M. Dolg and A. Savin, Eur. Phys. J. D, 1999, 6, 243-254.

77 E. Miliordos, K. Ruedenberg and S. S. Xantheas, Angew. Chem., 2013, 125, 5848-5851, (Angew. Chem., Int. Ed., 2013, 52, 5736-5739). 